\title{
CHARACTERIZATION OF ANTI-THYROGLOBULIN FACTORS IN HUMAN SERUM
}

\author{
By JOHN L. FAHEY AND HOWARD C. GOODMAN \\ (From the Metabolism Service, General Medicine Branch, National Cancer Institute and the \\ Section on Metabolism, Laboratory of Cellular Physiology and Metabolism, \\ National Heart Institute, Bethesda, Md.)
}

(Submitted for publication January 14, 1960; accepted March 3, 1960)

Investigations in patients with thyroid disease led to the discovery of serum factors which react like antibodies with thyroglobulin-containing extracts of human thyroid gland $(1,2)$. These serum factors have been shown to be among the $\gamma$-globulins (3). Pressman and colleagues (4) reported that the serum anti-thyroglobulin activity in one patient was associated with the $\gamma$-macroglobulins. Korngold, Van Leeuwen and Brener (5), utilizing gel-diffusion immunochemical techniques, recently reported an additional instance of anti-thyroglobulin activity associated with a $\gamma$-macroglobulin but found the activity in three other patients to be associated with the smaller 6.6S $\gamma$-globulins. Roitt, Campbell and Doniach (3), using gel-diffusion techniques to characterize the thyroid antigens, obtained data that can be interpreted as showing that the antibodies in the sera tested were the smaller, probably $6.6 \mathrm{~S}$, $\gamma$-globulins.

Recent studies have emphasized that $\gamma$-globulins should be regarded as an electrophoretic grouping of related but not identical proteins. They may be subdivided on the basis of size, hexose content and immunochemical properties into two major groups, the $6.6 \mathrm{~S}$ and $18 \mathrm{~S} \gamma$-globulins, with molecular weights of about 160,000 and $1,000,000$, respectively (6-8). Many physiologic and pathologic antibody activities belong in one or the other or, in some instances, in both of these $\gamma$-globulin fractions (9-11). In the present studies anion-exchange cellulose chromatography (12), which has proved to be particularly useful in $\gamma$-globulin subfractionation, was combined with electrophoretic and ultracentrifugal procedures to characterize the anti-thyroglobulin factors found in seven sera. In five patients the anti-thyroglobulin reactivity was found associated with $6.6 \mathrm{~S}$ $\gamma$-globulins and in two cases, with both $18 \mathrm{~S}$ and 6.6S $\gamma$-globulins.

\section{METHODS}

Anti-thyroglobulin activity in serum and serum fractions was determined by a modification of the tanned cell hemagglutination technique of Boyden (13) and Witebsky and colleagues (2). Thyroglobulin, ${ }^{1}$ obtained from human colloid goiter and found to be 86 per cent pure by ultracentrifugal analysis, was fixed to tanned red cells. The preparation of tanned cells, procedures for dilution of serum and serum fractions, and the technique of evaluating agglutination were essentially the same as those described elsewhere (14). The specificity of the tanned-cell hemagglutinin test for thyroglobulin antibodies was tested by absorption of reactive sera with a thyroglobulin preparation which was 96 per cent pure on ultracentrifugal analysis. All of the activity was removed by this preparation, providing support for the assumption that agglutination of the red cell preparation was due to anti-thyroglobulin activity.

Analytic paper electrophoresis, quantitative total serum protein measurements, and preparative electrophoretic procedures utilizing polyvinyl particle blocks have been described (8). Ultracentrifugal fractionation was carried out in the manner of Robbins, Petermann and Rall (15) utilizing a Spinco model $\mathrm{L}$ preparative ultracentrifuge. Sera were diluted 1:10 with $0.15 \mathrm{M} \mathrm{NaCl}$ solution and serum fractions were dialyzed thoroughly against the same solution prior to ultracentrifugation in the Spinco no. 40 rotor at $39,000 \mathrm{rpm}$ for 150 minutes. At the end of this time successive samples were collected from the top to the bottom of the ultracentrifuge tube by using a sampling syringe and needle. Determinations were made of anti-thyroglobulin activity and the results plotted in terms of the cumulative activity with increasing depth in the tube.

Anion-exchange cellulose chromatography was performed on columns of diethylaminoethyl-cellulose (16), employing $2 \mathrm{~g}$ of adsorbent and $1 \mathrm{ml}$ of serum. The starting and equilibrating potassium buffer was $0.02 \mathrm{M}$ phosphate, $\mathrm{pH} 8$. A $150 \mathrm{ml}$ gradient elution system providing a progressive rise in phosphate molarity to $0.25 \mathrm{M}$ while maintaining $\mathrm{pH} 8$, was used to elute the absorbed proteins from the column (8). Effluent from the column was collected in about 45 fractions and the protein content

\footnotetext{
1 The authors wish to thank Dr. J. Robbins for supplying the human thyroglobulin preparations used in these studies.
} 
estimated by measuring the optical density at $280 \mathrm{~m} \mu$ in a Beckman spectrophotometer. The effluent was then combined into 10 or more pools which were tested for anti-thyroglobulin activity after dialysis against $0.15 \mathrm{M}$ $\mathrm{NaCl}$ and without concentration.

\section{RESULTS}

Serological studies. Anti-thyroglobulin activity was tested in the serum of 118 patients with a variety of diseases (Table I), and 17 were found to have anti-thyroglobulin activity. Sera from 10 of the 11 patients with chronic thyroiditis had detectable anti-thyroglobulin activity. Although the diagnostic subdivision in Table I was made on clinical grounds, for it was not possible for us to obtain histologic confirmation of the diagnosis in each patient, the results showing the highest titers in chronic thyroiditis are consistent with the experience of Roitt and Doniach (17).

The observation of significant serum antithyroglobulin titers in four other diseases was of particular interest. One of these was a patient with Addison's disease and an enlarged thyroid gland, but no evidence of thyroid dysfunction. Patient H.L. had lupus erythematosus with no overt evidence of thyroid disease. Patient M.D., with a combination of purpura, Sjögren's syndrome and hyperglobulinemia and elevated serum macroglobulins (35 per cent), had a benign adenoma of the thyroid removed 10 years earlier. Patient E.B. had rheumatoid arthritis with evidence of thyroid dysfunction described elsewhere (18). Of interest is the finding that, in the lupus erythematosus sera and rheumatoid arthritis sera studied, only one serum from each group con-

TABLE I

Serum anti-thyroglobulin activity in disease

\begin{tabular}{lrrrr}
\hline \hline & & \multicolumn{3}{c}{$\begin{array}{c}\text { Hemagglutination titer } \\
\text { (reciprocal) }\end{array}$} \\
\cline { 3 - 5 } \multicolumn{1}{c}{ Clinical diagnosis } & $\begin{array}{c}\text { No. of } \\
\text { patients }\end{array}$ & $<10$ & $\begin{array}{r}10 \text { to } \\
1,280\end{array}$ & $\mathbf{1 , 2 8 0}$ to \\
\cline { 5 - 6 } & & & & \\
\hline Thyroid disease & 11 & 1 & 3 & 7 \\
$\quad$ Chronic thyroiditis & 9 & 8 & 1 & 0 \\
$\quad \begin{array}{l}\text { Suspected thyroiditis } \\
\text { Other thyroid diseases }\end{array}$ & 11 & 9 & 2 & 0 \\
Lupus erythematosus & 15 & 14 & 0 & 1 \\
Rheumatoid arthritis & 21 & 20 & 0 & 1 \\
Dysproteinemia* & 14 & 13 & 1 & 0 \\
Other diseases & 37 & 36 & 1 & 0 \\
$\quad$ Total & 118 & 101 & 8 & 9 \\
& & & &
\end{tabular}

* Macroglobulinemia 9, multiple myeloma 2, diffuse hypergammaglobulinemia 3 .
TABLE II

Sera used for characterization of anti-thyroglobulin factors

\begin{tabular}{llrl}
\hline Patient & \multicolumn{1}{c}{ Diagnosis } & $\begin{array}{c}\text { Anti-thyro- } \\
\text { globulin titer } \\
\text { (reciprocal) }\end{array}$ & $\begin{array}{c}\text { Serum } \\
\text {-globulins } \\
\text { gram \% }\end{array}$ \\
\hline Normal & Hashimoto's thyroiditis & 600,000 & 1.89 \\
M.H. & Hashimoto's thyroiditis & 12,800 & 1.58 \\
L.J. & Hashimon & $1.17( \pm 0.20)$ \\
F.S. & Hashimoto's thyroiditis & 16,000 & 2.19 \\
H.M. & Hashimoto's thyroiditis & $3,000,000$ & 2.35 \\
H.L. & Lupus erythematosus & 6,250 & 3.79 \\
E.B. & Rheumatoid arthritis & 6,250 & 1.60 \\
M.D. & Sjögren's syndrome* & 1,280 & 5.50 \\
\hline
\end{tabular}

* And other diseases; see text.

tained anti-thyroglobulin reactivity, although many of these patients had serum globulins which reacted with other tissue components (19).

Seven sera were chosen for further study. Table II lists the patients' diagnoses, serum antithyroglobulin titers and $\gamma$-globulin levels. The first four patients had the type of chronic thyroiditis diagnosed as Hashimoto's disease. The remaining three (H.L., M.D., E.B.) have been noted above. Absorption of these seven sera with a preparation shown to be at least 96 per cent thyroglobulin removed all reactivity with the thyroglobulin-extract-coated red blood cells and indicated that the reactive material was probably specific for thyroglobulin.

Electrophoretic studies. In all seven sera the total $\gamma$-globulin level was greater than normal (95 per cent normal confidence limits: 0.77 to $1.57 \mathrm{~g}$ per $100 \mathrm{ml}$ ). The diffuse appearance of the $\gamma$-globulin increase is apparent in Figure 1 where zone electrophoretic fractionation of the M.H. serum is presented. Examination of the block fractions for anti-thyroglobulin reactivity revealed this activity to be associated with the $\gamma$-globulins. The $\gamma$-globulin character of the reactivity in this and the other sera was confirmed by chromatographic studies reported below.

Ultracentrifugal studies. Ultracentrifugal studies were undertaken to determine the sedimentation properties of the $\gamma$-globulins possessing antithyroglobulin activity. Figure 2 illustrates the findings when whole sera were sedimented in a preparative ultracentrifuge under conditions which would cause only partial sedimentation of 6.6S $\gamma$-globulins but almost complete sedimentation of $18 \mathrm{~S} \gamma$-macroglobulins. Five sera (H.L., 


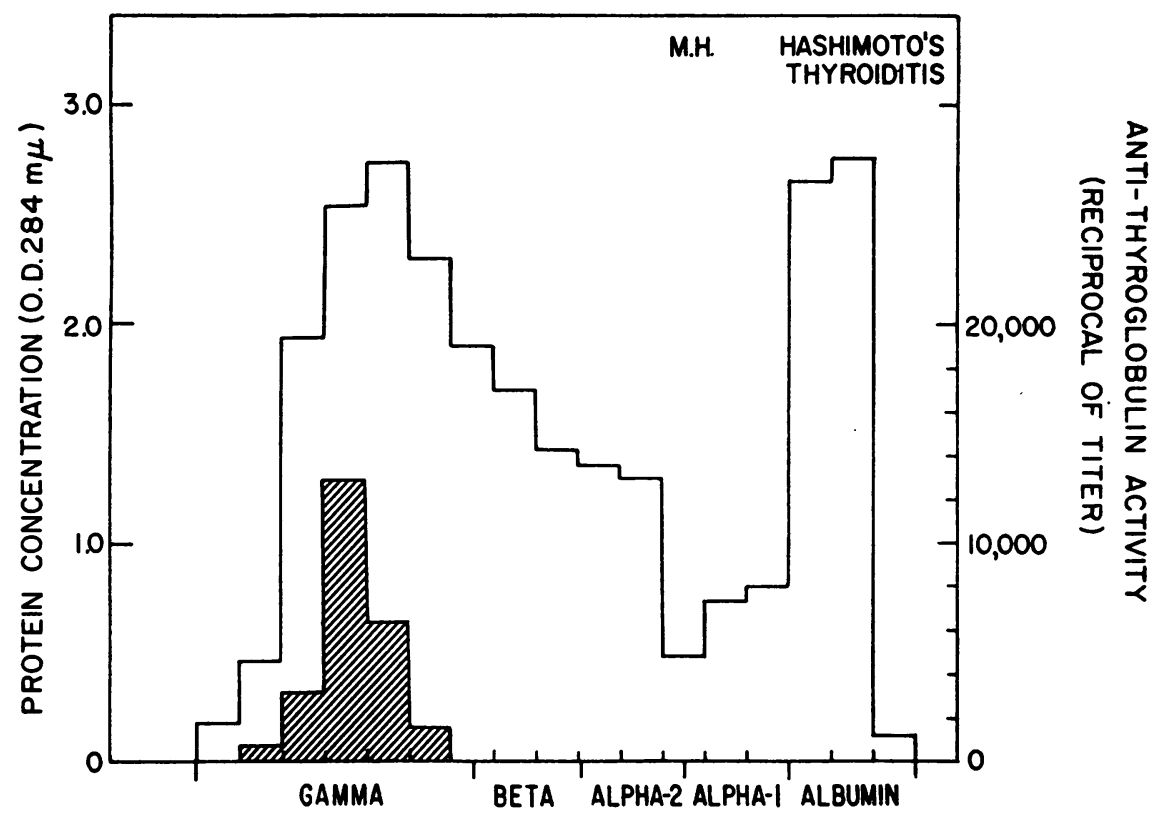

Fig. 1. Distribution of anti-thyroglobulin activity After zone (BLock) ELECTROPHORETIC FRACTIONATION OF THE M.H. SERUM. The shaded area represents the distribution of anti-thyroglobulin activity. The distribution of serum protein components was roughly determined by the location of pigment bands, pink in the $\beta$ region, blue in the $\alpha-2$ region and pale yellow in the albumin region, and was confirmed by analytic electrophoresis of the block sections.

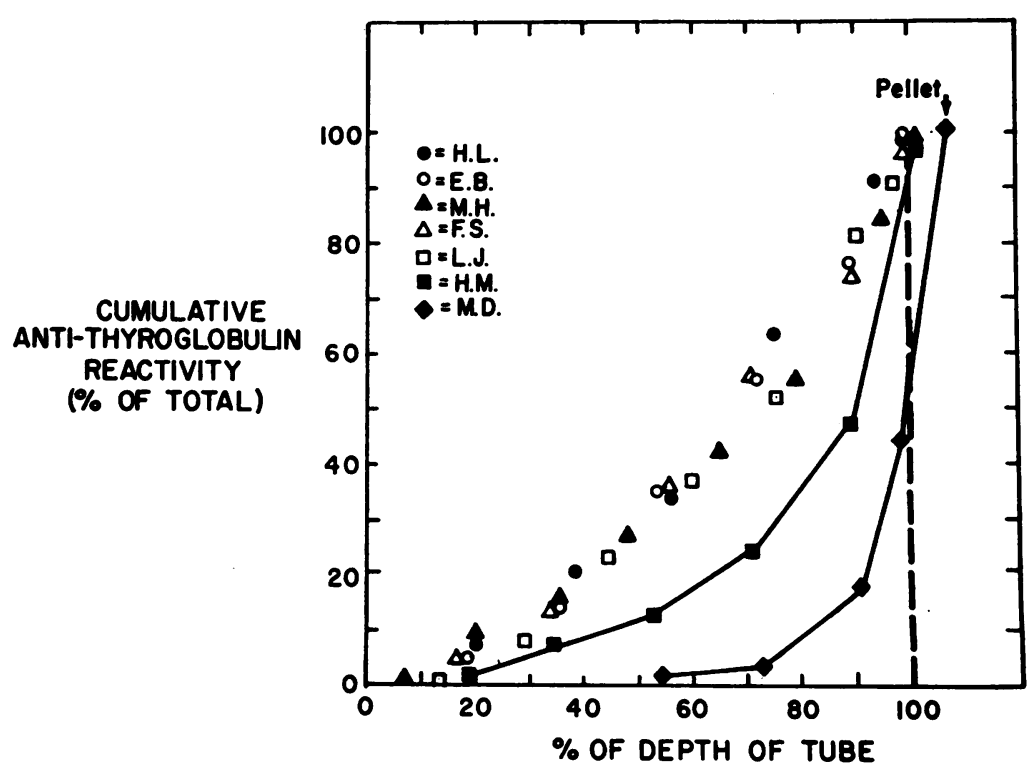

Fig. 2. Sedimentation Characteristics of anti-thyroglobulin acTIVITIES IN WHOLE SERUM. Ultracentrifugation was conducted in a preparative ultracentrifuge $(39,000 \mathrm{rpm}, 150$ minutes, $0.15 \mathrm{M} \mathrm{NaCl})$. After centrifugation successive samples were removed from each tube starting at the top. The distribution of anti-thyroglobulin reactivity is expressed in terms of cumulative per cent of the total in each tube. 


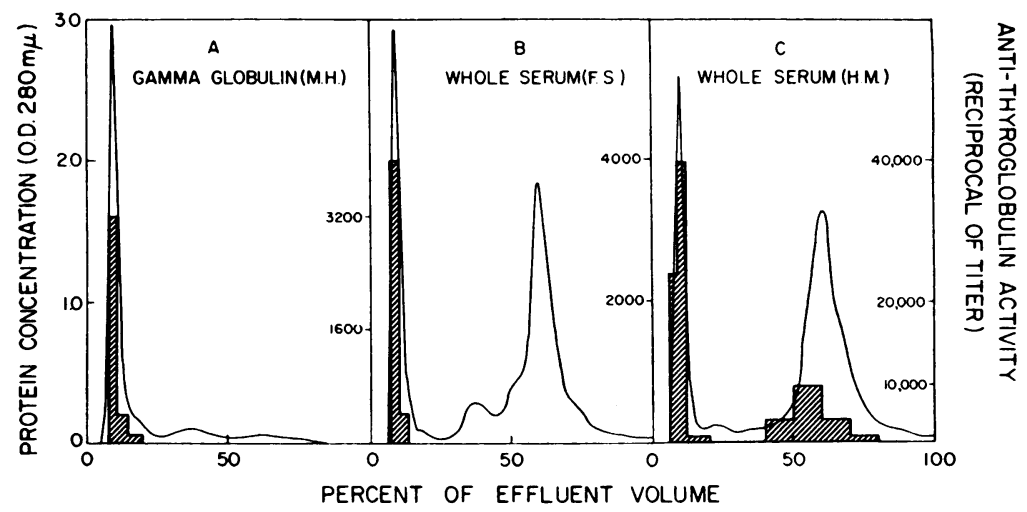

Fig. 3. Chromatographic distribution of anti-thyroglobulin acTIVITY IS SHOWN IN A, $\gamma$-GLOBULIN OBTAINED BY PREPARATIVE ELECTROPHORESis; iN B, WhOLE SERUM With the aCtivity in a SINGle Chromatogram REGION ; AND IN C, WHOLE SERUM WITH ACTIVITY IN TWO CHROMATOGRAM REgIONs. Chromatography was conducted on diethylaminoethyl-cellulose columns at $\mathrm{pH} 8$, and proteins were eluted by means of a gradient of increasing salt concentration, as noted in Methods.

E.B., M.H., F.S., L.J.) showed a uniform pattern of activity distribution, consistent with the sedimentation properties of $6.6 \mathrm{~S} \gamma$-globulins. In sera of H.M. and M.D., however, much of the activity sedimented more rapidly, suggesting that the anti-thyroglobulin activity was associated either with a molecule that sedimented more rapidly than the other serum factor or was associated with two types of molecules, at least one of which sedimented more rapidly.

Chromatographic studies. Whole sera and $\gamma$-globulins prepared by electrophoretic fractionation of whole sera were further fractionated by anion-exchange cellulose chromatography. Representative chromatograms together with the distribution of anti-thyroglobulin activity are presented in Figure 3. A single peak of antibody activity was found in the range of 5 to 15 per cent of the elution volume after chromatography of whole sera or $\gamma$-globulins from Patients M.H., F.S., E.E., M.H. and L.J. (Figure 3, A and B). The proteins in this peak are known to be $6.6 \mathrm{~S}$ $\gamma$-globulins (8), and finding of activity solely in this protein region is consistent with the uniform ultracentrifugal sedimentation properties of the activities in these same sera (Figure 2). Electrophoretic, chromatographic and ultracentrifugal observations were all consistent with the association of the anti-thyroglobulin activity with $6.6 \mathrm{~S}$ $\gamma$-globulin molecules.
The anti-thyroglobulin activities were more complex in the M.D. and H.M. sera. Anion-exchange cellulose chromatography revealed two peaks of antibody activity. The H.M. serum chromatogram is illustrated in Figure 3C. The M.D. chromatogram was qualitatively similar. Anti-thyroglobulin activity was found in the 5 to 15 per cent and also in the 50 to 80 per cent effluent region. With the H.M. serum, very low titers were obtained in the 15 to 40 per cent effluent regions (Figure 3C). The finding of activity in the 50 to 80 per cent region, which is composed primarily of $18 \mathrm{~S} \gamma$-macroglobulins, suggested that anti-thyroglobulin activity in this fraction was a property of $18 \mathrm{~S} \gamma$-globulins. The chromatographic separation of activity into two groups demonstrated that in the H.M. and M.D. sera two different antibodies possessed anti-thyroglobulin activity and distinguished these sera from the other five sera.

Ultracentrifugal studies, illustrated for the M.D. sera in Figure 4, demonstrated that the activity in the 60 to 80 per cent chromatogram effluent region sedimented more rapidly than that in the 5 to 15 per cent region. The sedimentation behavior of the anti-thyroglobulin activity in the 60 to 80 per cent chromatogram region was consistent with that of an 18S $\gamma$-globulin. These observations indicate that anti-thyroglobulin activity in these two sera were properties of both $6.6 \mathrm{~S}$ and $18 \mathrm{~S} \gamma$-glob- 
ulins and that these antibodies were separable by anion-exchange cellulose chromatography.

\section{DISCUSSION}

The present study confirms the observations that anti-thyroglobulin activity in man may be associated with $6.6 \mathrm{~S}$ or $18 \mathrm{~S} \gamma$-globulin molecules. In five patients the activity was associated solely with 6.6S $\gamma$-globulin molecules, but in two other patients anti-thyroglobulin activity was found with $6.6 \mathrm{~S}$ and $18 \mathrm{~S} \gamma$-globulins. Little is known of the role of antigen, host or disease factors in determining whether $18 \mathrm{~S}$ instead of $6.6 \mathrm{~S} \gamma$-globulin antibodies are to be formed. As far as we could determine in the present study the several serum antibody activities were reacting with the same substance in our thyroglobulin test. Thyroglobulin preparations, however, are not absolutely pure, and thyroglobulin is a large molecule likely to have a variety of antigenic sites. Antibodies to other large molecular substances, such as the erythrocyte isoagglutinogens, $\mathrm{Rh}$ factors and certain liver nucleoproteins, have also been found in both $6.6 \mathrm{~S}$ and $18 \mathrm{~S}$ protein fractions $(9-11,19$, $20)$. In each instance the potential antigen is a complex compound and the several antibodies could be directed against different antigenic sites, although this possibility has not been proved.

No clinical characteristic could be discerned which would help to distinguish between the patients with $18 \mathrm{~S}$ serum anti-thyroglobulin activities and those with only $6.6 \mathrm{~S}$ anti-thyroglobulin antibodies. Patient M.D. presented an unusual disease pattern, with long standing anemia, hyperglobulinemia, Sjögren's syndrome and repeated episodes of purpura, and she may have an abnormal immune mechanism manifest in multiple immune abnormalities, one being the serum anti-thyroglobulin antibody. The other patient, H.M., however, with a quite different disease pattern, not atypical of myxedema, had little in common with the former patient. It is also worth noting that the $18 \mathrm{~S}$ macroglobulin level in the H.M. serum was normal (2.7 per cent).

That the clinical and immunological significance of $18 \mathrm{~S}$ as distinct from $6.6 \mathrm{~S}$ antibodies remains largely unexplored has been in part due to difficulties in separating and identifying the different antibody forms. Anion-exchange cellulose chromatography has greatly facilitated the separation of physicochemically different antibodies in other antibody studies (9-11) as well as in the present

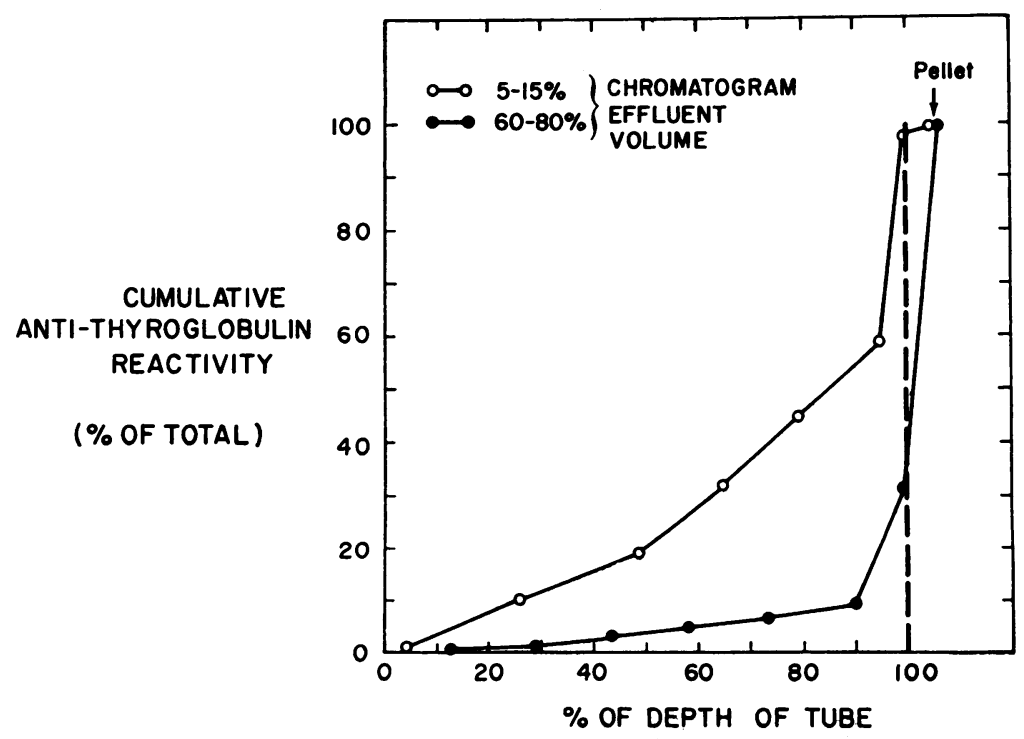

Fig. 4. Differences in the Sedimentation Characteristics of two ANTI-THYROGLOBULIN COMPONENTS ( 5 TO 15 AND 60 TO 80 PER CENT) OBTAINED BY CHROMATOGRAPHIC FRACTIONATION OF SERUM OF M.D. Ultracentrifugation was carried out as in Figure 2. 
study of serum anti-thyroglobulin activity. Further application of these procedures may be expected to provide new insight into the nature of antibodies in thyroid and other diseases.

\section{SUMMARY}

Sera from 118 patients with a variety of diseases were examined for anti-thyroglobulin activity by the agglutination of red blood cells treated with tannic acid and coated with human thyroglobulin. Anti-thyroglobulin activity was found most commonly but not exclusively in patients with clinical evidence of chronic thyroiditis. The serum factors responsible for anti-thyroglobulin activity were characterized in detail in seven sera, including four from patients with chronic thyroiditis.

Anti-thyroglobulin activity was found only in the $\gamma$-globulin fraction of the serum proteins. The activity was found to be a single component with the sedimentation characteristics of $6.6 \mathrm{~S}$ $\gamma$-globulins in five sera. In two sera, however, anti-thyroglobulin activity was found in two components with the sedimentation characteristics of $6.6 \mathrm{~S}$ and $18 \mathrm{~S} \gamma$-globulins, respectively.

The $6.6 \mathrm{~S}$ and $18 \mathrm{~S}$ types of anti-thyroglobulin activity could be separated and their recognition facilitated by anion-exchange cellulose chromatography. Chromatographic separation, in addition, made possible quantitative measurement of each of the two types of activity.

The possible role of antigen and host factors in determining the type of antibody response was briefly considered. No common clinical feature in the two patients producing $18 \mathrm{~S}$ anti-thyroglobulin antibodies could be found which would distinguish these two patients from the 6.6S antibody-producing patients.

\section{ACKNOWLEDGMENTS}

We wish to thank Drs. J. E. Rall, K. J. Block and J. Nassou for making available sera utilized in these studies. We also are indebted to Mr. Robert Bowser for help in the anti-thyroglobulin assays and ultracentrifugal procedures, Miss Ann P. Horbett for zone electrophoretic fractionations and Miss Mary E. Lawrence for assistance with the chromatography.

\section{REFERENCES}

1. Roitt, I. M., Doniach, D., Campbell, P. N., and Hudson, R. V. Auto-antibodies in Hashimoto's disease (lymphadenoid goitre). Lancet 1956, 2, 820 .

2. Witebsky, E., Rose, N. R., Terplan, K., Paine, J. R., and Egan, R. W. Chronic thyroiditis and autoimmunization. J. Amer. med. Ass. 1957, 164, 1439.

3. Roitt, I. M., Campbell, P. N., and Doniach, D. The nature of the thyroid auto-antibodies present in patients with Hashimoto's thyroiditis (lymphadenoid goitre). Biochem. J. 1958, 69, 248.

4. Pressman, D., James, A. W., Yagi, Y., Hiramoto, R., Woernley, D., and Maxwell, W. T. Rapidly sedimenting properties of specifically precipitating component of a Hashimoto's disease serum. Proc. Soc. exp. Biol. (N. Y.) 1957, 96, 773.

5. Korngold, L., Van Leeuwen, G., and Brener, J. L. Determination of the molecular weight of different autoprecipitins in Hashimoto's disease by a new immunologic method. J. Lab. clin. Med. 1959, 53, 517.

6. Müller-Eberhard, H. J., and Kunkel, H. G. The carbohyrate of $\gamma$-globulin and myeloma proteins. J. exp. Med. 1956, 104, 253.

7. Franklin, E. C., and Kunkel, H. G. Immunologic differences between the 19S and 7S components of normal human $\gamma$-globulin. J. Immunol. 1957, 78, 11.

8. Fahey, J. L., and Horbett, A. P. Human gamma globulin fractionation on anion exchange cellulose columns. J. biol. Chem. 1959, 234, 2645.

9. Fahey, J. L. Separation of serum antibody activities by anion-exchange cellulose chromatography. Science 1960, 131, 500.

10. Fahey, J. L., and Morrison, E. Separation of $6.6 \mathrm{~S}$ and 18S gamma globulins with isohemagglutinin activity. J. Lab. clin. Med. In press.

11. Goodman, H. C., Fahey, J. L., Malmgren, R. A., and Brecher, G. Separation of factors in lupus erythematosus serum reacting with components of cell nuclei. Lancet 1959, 2, 382.

12. Sober, H. A., Gutter, F. J., Wyckoff, M. M., and Peterson, E. A. Chromatography of proteins. II. Fractionation of serum protein on anion-exchange cellulose. J. Amer. chem. Soc. 1956, 78, 756.

13. Boyden, S. V. The adsorption of proteins on erythrocytes treated with tannic acid and subsequent hemagglutination by antiprotein sera. J. exp. Med. 1951, 93, 107.

14. Goodman, H. C., and Bowser, R. In preparation.

15. Robbins, J., Petermann, M. L., and Rall, J. E. Thyroglobulin in serum after $I^{131}$ therapy. II. Sedimentation in the ultracentrifuge. J. biol. Chem. 1954, 208, 387. 
16. Peterson, E. A., and Sober, H. A. Chromatography of proteins. I. Cellulose ion-exchange adsorbents. J. Amer. chem. Soc. 1956, 78, 751.

17. Roitt, I. M., and Doniach, D. Human auto-immune thyroiditis: Serological studies. Lancet 1958, 2, 1027.

18. Black, R. L., Reefe, W. E., David, J. R., Block, K. J., Ehrlich, G. E., and Bunim, J. J. Dexamethasone: Antirheumatic properties, hormonal effects and side reactions: A sixteen month study. Arth. Rheum. In press.
19. Goodman, H. C., Fahey, J. L., and Malmgren, R. Serum factors in lupus erythematosus and other diseases reacting with cell nuclei and nucleoprotein extracts: Electrophoretic, ultracentrifugal and chromatographic studies. J. clin. Invest. In press. 1960, 39 (Oct.).

20. Campbell, D. H., Sturgeon, P., and Vinograd, J. R. Separation of complete and incomplete $\mathrm{Rh}$ antibodies by centrifugation. Science 1955, 122, 1091. 